\title{
RISK ANALYSIS ON ORGANOCHLORINE PESTICIDES RESIDUE IN POTATO AND CARROT FROM CONVENTIONAL AND ORGANIC FARMS IN CITARUM WATERSHED AREA, WEST JAVA PROVINCE, INDONESIA
}

\author{
Suphia Rahmawati ${ }^{1)}$, Listya Chandra Kirana ${ }^{2)}$ Minoru Yoneda ${ }^{3)}$ dan Katharina Oginawati' ${ }^{2)}$ \\ 1) Universitas Islam Indonesia (UII), Environmental Engineering Program , Jl. Kaliurang KM 14,5, Besi, Sleman, \\ Yogyakarta \\ 2) Institut Teknologi Bandung (ITB), Dept. of Environmental Engineering, Jalan Ganesha 10, Bandung \\ ${ }^{3)}$ Kyoto University, Dept. of Environmental Engineering, Katsura campus Nishikyo-ku, Kyoto 615-8540, Japan \\ suphia.rahmawati@uii.ac.id
}

\begin{abstract}
Six samples of carrot and potatoes were collected from conventional and organic farms. Organochlorine pesticides $(O C P s)$ residue was analyzed using liquid-liquid extraction. The concentration of OCPs residue together with the consumption pattern were used to calculate the potential risk. Estimated Daily Intake (EDI) of OCPs residue in carrots and potatoes both from conventional and organic farms were below the standard given in SNI 7313:2008 and the Maximum Residue Limit (MRLs) from USEPA. Hazard quotient (HQ) and Hazard Index (HI) as effect analysis were below the unity, thus there may not be a concern for non-carcinogenic effect. Risk analysis on cancer effects indicated that potatoes samples were above the recommended risk by EPA $\left(10^{-6}\right)$. In addition, risk of potatoes samples from organic samples was higher compare to that of the conventional farm. Cancer risk analysis of carrot samples were found below the recommended risk by EPA. Cancer risk effect of carrot samples from conventional farm was slightly higher compare to that of the organic farm.
\end{abstract}

Kata Kunci : organochlorine pesticide, carrot, potatoes, Citarum watershed

\section{INTRODUCTION}

OCPs such as DDT, chlordane, dieldrin, and heptachlor are included in the group of persistent organic pollutant (POP). These compounds become a big concern in the environment due to their resistance, global transport, distribution and toxicity (Wania and Mackay, 1996). Moreover, OCPs have been linked to carcinogenicity and endocrine disruption in mammals since its bioaccumulation in fatty tissues and biomagnification through food chains (Patlak, 1996).

OCPs were already banned in developed countries; however some of developing countries still use these pesticides due to the low cost, its effectiveness and also the leftover from the previous stock. As results, OCPs residue remains as major pollution in environment such as soil (Shegunova, et al., 2007; Li, et al., 2008; Hildebrandt, et al., 2009; Jiang et al., 2009), surface water and sediment (Zou, et al., 2006; Imo et al., 2006; Tang, et al., 2007; Samoh and Ibrahim, 2009). In Indonesia, OCPs were detected in several river water such as Siak River in Sumatra Island (Munawir, 1996), Membramo River in Irian Jaya (Munawir, 2005), Ciliwung River (Sudaryanto, 2006), and coastral area in Sulawesi (Munawir, 2000). Several studies also show the accumulation of OCPs in freshwater and coastral fish (Sudaryanto, 2006), vegetables (Yunike, 2009), and groundwater 
(Sabdono, et al., 2008). There is an assumption in Indonesia that OCP pollution was already stopped since the use of OCP was banned by government regulation. However, Rochmanti (2009) found that OCP is still used by farmer for agricultural purpose in Citarum Watershed area, Java Island.

Pesticides can be applied using several methods. Most pesticides are sprayed directly on the crop or soil, while some other are injected into the soil or applied as granules or in a seed treatment. Applications of pesticides depend on the crop type and age, target, formulation, application technique and weather condition. In the environment, pesticides transport into a cycle. Spraying application will distribute perticides on soil, crop foliage, loss due to the drift, becomes crop residue (Van der Werf, 1996 and Huddleston, 1994 or it can be removed by degradation or dipersion. Plants may accumulate OCPs with different pathways such as from the root uptake, contamination of foliage and fruits by soil particles, and deposition from air particles (Gonzalez, et al., 2003). Therefore, contamination in plant will have a great influence on the total daily intake of OCPs.

Nowadays, food quality and safety become an important issue worldwide. Consumers have become more concerned that their food should be containing high nutrition and are free from chemical residues. This resulted in increasing demand for the organic product. Organic farming avoids the use of synthetic fertilizer and pesticides. However, organics crops are planted in soil that might be contaminated by persistent organic chemical at low concentration from the past application. Therefore, the objectives of this study are as follows: (1) To investigate OCPs residue and its level in vegetables (potatoes and carrot) planted using conventional agricultural and organic farming, (2) to estimate the daily intake of vegetables using potatoes and carrots as examples (3) to compare the obtained daily intake with Acceptable Daily Intake (ADI) and Maximum Residue Limit (MRLs) (4) to analyze human risk of OCPs exposure on local community.

\section{MATERIALS AND METHODS}

\subsection{Sampling location}

Samples were collected directly from farmer during harvesting time on March 2010. There are six sampling points each for conventional agricultural and organic farming area. Sampling location of conventional agricultural was located in Kertasari and Pacet subdistricts at the upper area of Citarum watershed, West Java, Indonesia (7¹2’5.2”S; 107³9’45.5”E). This area is developed for agricultural area up to thousands of hectares. Kertasari subdistricts are dominated with vegetables 
commodities such as cabbage, carrots, onion and potato. While Pacet subdistrict that is located in lower area is dominated by paddy field. Thus, the use of pesticides to control plant pest is indispensable. Organic carrots and potatoes were collected from organic farming of Gambung Village, Pasir Jambu sub district, Bandung district (76'10.59”S; 107²8'50.51'E). This location was listed in organic commodity directory by Ministry of Agriculture. This location also produces vegetables such as carrots, potatoes, and cabbage. This study focuses on carrots and potatoes commodity only.

\subsection{Sample analysis}

One kilogram of carrots and potatoes from each sampling points were collected, put into clean polyethylene bag, and frozen prior to analysis. Soil samples were also collected in the sampling point, dried and sieved before being analyzed. Samples preparation and analysis were conducted at Laboratory of Pesticide Residue in Bogor, Indonesia. Analysis method was adopted from The National Pesticide Committee based on liquid-liquid extraction methods.

In the laboratory carrot and potatoes samples were pilled and cut into small pieces. 25 gr of sample was homogenized with $100 \mathrm{ml}$ of acetone. For the soil sample, $25 \mathrm{gr}$ of dried and sieved soil samples were mixed with $100 \mathrm{ml}$ of acetone and shaken twice using shaker in $80 \mathrm{rpm}$ for 20 minutes. Both of samples were filtered, added by $50 \mathrm{ml}$ of $\mathrm{n}$-hexane to the flask, shaken twice until the layers were allowed to separate. The upper hexane layer was concentrated to a small volume of $10 \mathrm{ml}$. The cleanup was carried out by florisil and natrium sulfate anhydrate. Filtrate was then evaporated until $1 \mathrm{ml}$ volume, eluted with acetone until final volume of $10 \mathrm{ml}$. Only analytical grade chemicals were used in this research.

Samples were analyzed using Varian 450 Gas Chromatograph equipped with ECD detector with VF $1701(30 \mathrm{~m} \times 0.25 \mathrm{~mm} \times 0.25 \mu \mathrm{m})$ and VF-5 (30 $\mathrm{m} \times 0.25 \mathrm{~mm} \times 0.25 \mu \mathrm{m})$ columns. Injector and detector temperature were $240^{\circ} \mathrm{C}$, column temperature was $230^{\circ} \mathrm{C}$. The column was performed in initial temperature of $150^{\circ} \mathrm{C}$ for $0.5 \mathrm{~min}$, then programmed for two levels temperature: at rate $20^{\circ} \mathrm{C} / \mathrm{min}$ to $200^{\circ} \mathrm{C}$ and held for 3 minutes; at rate $25^{\circ} \mathrm{C} / \mathrm{min}$ to $250^{\circ} \mathrm{C}$ and held for 17 minutes. Nitrogen gas was used as a carrier gas with velocity of $40 \mathrm{ml} / \mathrm{min}$, speed recording was $5 \mathrm{~mm} / \mathrm{min}$ and sensitivity was $10^{2}$.

A standard-mixture containing 6 organochlorine compounds (Aldrin, Dieldrin, DDT, Endrin, Heptachlor and Lindane) and a single standard of endosulfan were obtained from Supelco with the 
purities $>98 \%$. A stock solution containing standard solution was prepared by dissolving $1.0 \mathrm{~mL}$ standard solutions $(2000 \mathrm{mg} / \mathrm{L})$ in a $50 \mathrm{~mL}$ volumetric flask with acetone and stored in brown glass bottles with Teflon cap. Working solution was prepared every month by diluting stock solution into several concentrations: $1.25,5,10,20$, and $40 \mu \mathrm{g} / \mathrm{L}$ respectively and stored at $4{ }^{\circ} \mathrm{C}$. The quality assurance was executed by the internal standard methods. Contamination control was conducted during analysis; washing and cleaning the equipment carefully and elution with solvent prior to analysis to avoid contamination. Monitoring of blank levels of solvents, purities of other materials, procedural analysis, and recovery of spike samples, linearity and response detector were monitored.

Calibration curve was obtained from peak area versus concentrations based on the linear regression. Accuracy and repeatability of the method were assessed by adding known amounts of organochlorine pesticides. Limit of detection were obtained from three times of ratio between standard deviation and slope of calibration curvewhile limit of quantification of each compound was obtained from ten times of the same ratio. Standard deviation was calculated from the peak of area from the lowest concentration repeated seven times. Recovery rate was determined by spiking a known concentration of organochlorine standard in water and soil samples and repeated for seven times. Recovery analysis was 90-92\% for lindane, heptachlor, dieldrin, endrin, aldrin, DDT, and endosulfan (OCPs). Limit of detection were obtained from three times of ratio between standard deviation and the slope of calibration curve. Limit of detection for OCPs has a range from $\mu \mathrm{g} / \mathrm{L}$ for water samples and $\mu \mathrm{g} / \mathrm{kg}$ for sediment samples. All samples were expressed in $\mu \mathrm{g} / \mathrm{kg}$.

\subsection{Risk Analysis}

Risk analysis of vegetables consumption on human health will be based on some guidelines provided by different international organizations as follows:

\section{A. Accaptable Daily Intake (ADI)}

Acceptable Daily Intake (ADI) is an amount of a specific substance which was originally applied for a food additive and later also for drug or pesticide in drinking water or food that can be orally ingested on daily basis over a lifetime without an appreciable health risk (WHO, 1987). ADI as an approach of toxicological evaluation was initiated by the Joint FAO/WHO Expert Committee on Food Additives in 1961 by collecting all relevant data, ascertaining the completeness of the available data, determining the no-effect level using the most sensitive indicator of the toxicity, and applying an appropriate safety factor to arrive at the ADI for man. The ADI is usually defined as 
mg per kg body weight per day. The higher value of ADI means that the larger the amount of a compound that is safe for a regular ingestion. However, this formulation did not take consideration of consumption rates and different eating habits. To be compared with ADI, the individual exposure was calculated based on the Estimated Daily Intake (EDI) which is determined based on the Equation 1 below:

$$
E D I=\frac{D C * C C}{B W}
$$

Where EDI (ng/kg body weight day) is the estimated daily intake, DC is food (fish) daily consumption, $\mathrm{CC}$ is average concentration of each $\mathrm{OCP}$, and $\mathrm{BW}$ is body weight, for which $60 \mathrm{~kg}$ is typical (IPCS, 2006). If EDI is lower than ADI, it considers that the consumption is safe. On the other hand if EDI is higher than ADI then it considers that the consumption has a potential problem.

\section{B. Minimal Risk Level (MRL)}

The second method is compared with Minimal Risk Level (MRL) formulated by US FDA to evaluate the chronic effects. MRLs were proposed by the Agency for Toxic Substances and Disease Registry (ATSDR) to estimate the daily human exposure to a hazardous substance that is likely to be without appreciable risk of adverse non-cancer health effects over a specified duration of exposure. MRLs are divided into three durations; acute (1-14 days), intermediate (15-364 days) and chronic (1 year or longer) for the oral and inhalation routes of exposure (ATSDR, 2010). MRLs are generally based on the most sensitive substance-induced end point considered to be of relevance to humans. Serious health effects such as irreparable damage to the liver or kidneys, or birth defects are not used as a basis for establishing MRLs, thus exposure to a level above the MRL does not mean that adverse health effects will occur. However, most of the MRLs have some degrees of uncertainty because of the lack of precise toxicological information on the people who might be the most sensitive (e.g., infants, elderly, and nutritionally or immunologically compromised) to effects of hazardous substances.

\section{Risk Characterization}

If the exposure happens for longer time ( 7 until lifetime), therefore the intake equation can be used to estimate the chronic intake (Chronic daily intake) by adjusting the exposure time parameter, as follows:

$$
\text { Chronic dose intake }(C D I)=\frac{C * I R * E F * F I E D}{B W * A T}
$$


CDI is chronic dose intake (ng/kg-day), $\mathrm{C}$ is measured OCPs concentration in fish samples (ng/gr wet weight), IR is ingestion rate ( $\mathrm{gr} / \mathrm{meal}$ ) which should be in conjunction with an exposure frequency of 365 days/year, EF is Exposure Frequency (meals/year), FI is Fraction Ingested from contaminated soil (=1, unitless), BW is body weight $(\mathrm{kg})$, and AT is averaging time (days/year).

In carcinogen effects, risk is estimated as the incremental of probability of an individual developing cancer over a lifetime as a result of exposure to the potential carcinogen. According to the guidelines for carcinogenic risk assessment (USEPA, 1989), slope factor (SF) converts the estimated daily intake averaged over a lifetime of exposure directly to incremental risk of an individual developing cancer (Table 1). With the assumption that the exposure from the environment is lower than the treated animal, the slope factor is a constant and the risk will be directly related with the intake (Equation 3). However, this linear equation is valid only at low risk levels (below estimated risk 0.01). For higher risk level, one-hit equation (USEPA, 1989) should be applied (Equation 4).

$$
\begin{aligned}
& \text { Risk }=C D I \times S F \\
& \text { Risk }=1-\exp (C D I \times S F)
\end{aligned}
$$

Table 1. Toxicity value of potential carcinogenic effects (Slope factor)

\begin{tabular}{ccccl}
\hline Chemical & Slope factor $\mathbf{( S F})\left(\mathbf{m g} / \mathbf{k g}-\right.$ day $^{\mathbf{- 1}}$ & Weight-of-evidence classification & Type of cancer & SFBasis / SF Source \\
\hline Lindane & $1.30 \mathrm{E}+00$ & $\mathrm{~B} 2 / \mathrm{C}$ & - & Diet/IRIS \\
Aldrin & $1.70 \mathrm{E}+01$ & $\mathrm{~B} 2$ & - & Diet/IRIS \\
Heptachlor & $4.50 \mathrm{E}+00$ & $\mathrm{~B} 2$ & - & Water/IRIS \\
Dieldrin & $1.60 \mathrm{E}+01$ & $\mathrm{~B} 2$ & - & Water/IRIS \\
DDT & $3.40 \mathrm{E}-01$ & $\mathrm{~B} 2$ & - & Water/IRIS \\
Endrin & n.a & D & - & n.a \\
Endosulfan & n.a & n.a & n.a & n.a \\
\hline
\end{tabular}

Source :USEPA, IRIS (2011)

For noncarcinogenic effects, risk is evaluated by comparing an exposure level over a specified period time (e.g. lifetime) with a reference dose derived for a similar exposure period (Table 2). This ratio of exposure over toxicity is called a hazard quotient (HQ) which is expressed by equation below:

$$
\text { Hazard Quotient }(H Q)=E / R f D
$$

Where $\mathrm{E}$ is exposure level or intake, RfD is a reference dose. It should be noted that $\mathrm{E}$ and $\mathrm{RfD}$ are expressed in the same unit and represent the same exposure period. If the exposure level exceeds the RfD or the hazard quotient exceeds unity, there may be a concern for potential noncancer effect. For chronic exposure E can be replaced with CDI. 
At most of polluted sites, the potential health effects there might be more than one chemical that might pose a potential hazard. Estimating risk or hazard potential by considering only one chemical might underestimate the risks. Therefore, the overall potential for cancer and noncancer effects possed by multiple chemicals should be assessed based on EPA Guidelines for the Health Risk Assessment of Chemical Mixtures (EPA, 1986). Equation 6 and 7 are used to calculate the multiple risks of carcinogenic effect and noncarcinogenic effect.

$$
\operatorname{Risk}_{T}=\sum \text { Risk }_{i}
$$

Where Risk $_{\mathrm{T}}$ is the total cancer risk, expressed as a unitless probability and Risk $\mathrm{i}_{\mathrm{i}}$ is the risk estimate for the $\mathrm{i}^{\text {th }}$ substance

$$
\text { Hazard Index }(H I)=\frac{E_{1}}{R f D_{1}}+\frac{E_{2}}{R f D_{2}}+\cdots+\frac{E_{i}}{R f D_{i}}
$$

Where $E_{i}$ is exposure level (or intake) for the $\mathrm{i}^{\text {th }}$ toxicant and $\operatorname{RfD}_{\mathrm{i}}$ is reference dose for the $\mathrm{i}^{\text {th }}$ toxicant. For chronic exposure, $\mathrm{E}_{\mathrm{i}}$ can be replaced as $\mathrm{CDI}_{\mathrm{i}}$

\begin{tabular}{|c|c|c|c|c|}
\hline Chemical & $\begin{array}{l}\text { Chronic RfD } \\
\text { (mg/kg-day) }\end{array}$ & $\begin{array}{c}\text { Confidence } \\
\text { Level }\end{array}$ & Critical Effect & $\begin{array}{l}\text { Uncertainty and modifying } \\
\text { factor }\end{array}$ \\
\hline Lindane & $3.00 \mathrm{E}-04$ & medium & Liver and kidney toxicity & $\mathrm{UF}=1000(\mathrm{H}, \mathrm{A}, \mathrm{S}), \mathrm{MF}: 1$ \\
\hline Aldrin & $3.00 \mathrm{E}-05$ & medium & Liver Toxicity & $\mathrm{UF}=1000(\mathrm{H}, \mathrm{A}, \mathrm{L}), \mathrm{MF}: 1$ \\
\hline Heptachlor & 5.00E-04 & low & Liver weight increase in male & $\mathrm{UF}=300, \mathrm{MF}: 1$ \\
\hline Dieldrin & $5.00 \mathrm{E}-05$ & medium & Liver leison & $\mathrm{UF}=100(\mathrm{~A}$ and $), \mathrm{MF}: 1$ \\
\hline DDT & $5.00 \mathrm{E}-04$ & medium & Liver leison & $\mathrm{UF}=100(\mathrm{~A}$ and $), \mathrm{MF}: 1$ \\
\hline Endrin & $3.00 \mathrm{E}-04$ & medium & $\begin{array}{l}\text { Mild histological lesions in liver, occasional } \\
\text { convulsions }\end{array}$ & $\mathrm{UF}=100(\mathrm{~A}, \mathrm{H}), \mathrm{MF}: 1$ \\
\hline Endosulfan & $6.00 \mathrm{E}-03$ & medium & Reduced body weight gain in males and females & $\mathrm{UF}=100$ \\
\hline
\end{tabular}

Table 2. Toxicity value of potential non-carcinogenic effects (RfD)

\section{RESULTS AND DISCUSSION}

\subsection{OCPs Residue}

Summary of OCP average concentration in both carrot and potatoes was presented in Table 3 . Average concentration of OCP from conventional farm was slightly higher compared to that of the organic farm except for lindane. Carrot samples contain more OCPs compare to potatoes. It was suggested that carrot plantation received more OCPs application than potatoes. However, OCPs uptake mechanism by carrot and potatoes should be taken into account.

Table 3. Average concentration of OCPs in carrot and potatoes samples $(n=6)$.

\begin{tabular}{lcccc}
\hline \multirow{2}{*}{ OCP } & \multicolumn{2}{c}{ Carrot $(\mu \mathrm{g} / \mathrm{kg} \mathrm{ww})$} & \multicolumn{2}{c}{ Potatoes $(\mu \mathrm{kg} / \mathrm{kgw})$} \\
& Organic & Conventional & Organic & Conventional \\
\hline Lindane & 0.97 & 1.63 & 2.07 & 6.58 \\
Aldrin & $\mathrm{ND}$ & 2.30 & 4.80 & ND \\
Heptachlor & 0.50 & 2.05 & 1.35 & 0.73 \\
Dieldrin & 2.50 & 1.40 & ND & ND
\end{tabular}




\begin{tabular}{lcccc} 
DDT & 0.50 & ND & ND & ND \\
Endrin & 0.80 & 0.95 & 0.70 & ND \\
Endosulfann & ND & ND & 0.55 & ND \\
\hline
\end{tabular}

ND is below detection limit.

This research results also show that maximum concentration of OCPs residue in carrot and potatoes was below the maximum residue limit according to SNI 7313:2008 (Table 4).

Table 4. Comparison of OCPs residue in this research with Indonesian OCP residue standard for food

\begin{tabular}{lcccccc}
\hline \multirow{2}{*}{ OCP } & \multicolumn{3}{c}{$\begin{array}{c}\text { Max. concentration in Potatoes } \\
(\mu \mathrm{g} / \mathrm{kg} w w)\end{array}$} & \multicolumn{3}{c}{$\begin{array}{c}\text { Max. concentration in carrot } \\
(\mu \mathrm{g} / \mathrm{kg} \text { ww })\end{array}$} \\
\cline { 2 - 7 } & Organic & Conventional & MRL & Organic & Conventional & MRL \\
\hline Lindane & 3.3 & 19.8 & 50 & 1.5 & 3.5 & 200 \\
Aldrin & 4.8 & 1.2 & 100 & - & 2.3 & 100 \\
Heptachlor & 2.1 & - & $50^{*}$ & 0.5 & 2.4 & 200 \\
Dieldrin & - & - & 100 & 4.1 & 2.5 & 500 \\
DDT & - & - & $1000^{*}$ & 0.5 & - & $1000^{*}$ \\
Endrin & 0.7 & - & - & 0.9 & 1.2 & - \\
Endosulfan & 0.7 & - & 200 & - & - & 200 \\
\hline * No specific standard only in vegetables & & & & &
\end{tabular}

MRL = Maximum Residue Limit

Figure 1 and 2 show OCP residue in soil taken from carrot and potatoes plantation from conventional and organic farms. Heptachlor was found dominating (63\% of the total samples) for both carrot and potatoes area in both types of farms followed by lindane $(25 \%)$ while other was detected in one or two samples. DDT was not detected in conventional farm but was detected in organic farm with low concentration $(0.5 \mu \mathrm{g} / \mathrm{kg} \mathrm{ww})$. Aldrin was detected only in one sampling point (CC-3) in conventional farm. In contrast, dieldrin was not detected in all sampling points.

OCP residue in soil has significantly different tendency with OCP residue in carrots and potatoes. In carrot plantation at conventional farm, only heptachlor was detected in the soil. Moreover, the OCP residue in carrot area was significantly lower compared to potatoes area at conventional farm. One of the reasons for this phenomenon is because carrot farms are mostly located in sloping area while potatoes farms are in relatively flat area. The correlation between slopes and concentration of OCP in the soil was also explained by Yunike (2009). She found that OCP residues in slope area in Kertasari sub district of Bandung regency were lower than in flat area. In case of organic farm, OCPs residue in carrot and potatoes plantation was relatively similar, probably due to the relatively flat area.

Organic farm approach was actually introduced to avoid the use of synthetic fertilizer and pesticides hereinafter will reduce chemical residues potential contamination in food. However, this research shows that OCPs residues were still being found in organic farming, both in soil and crops. There is possibility that the residues detected in this research came from the previous usage, since OCPs 
residues can be persistent in soil. Volatile characteristic of OCPs might increase the possibility. OCPs residue from previous usage can remain in the atmosphere and be transported by wind to the surrounding area. That residue can be disposed into the soil during rainy season; furthermore, it can be adsorbed by the crops.
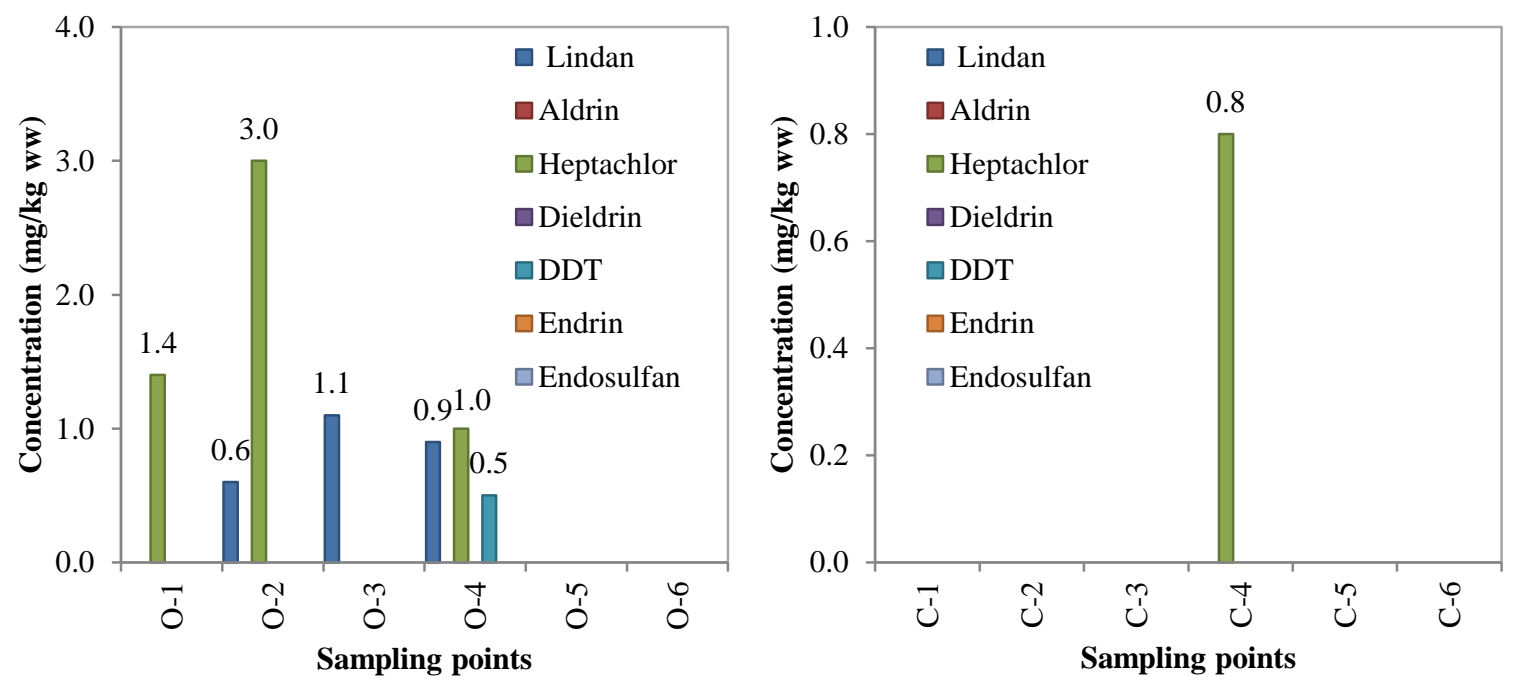

Figure 1. OCPs residue in soil taken from carrot plantation of organic farm $(\mathrm{O})$ and conventional farm (C)
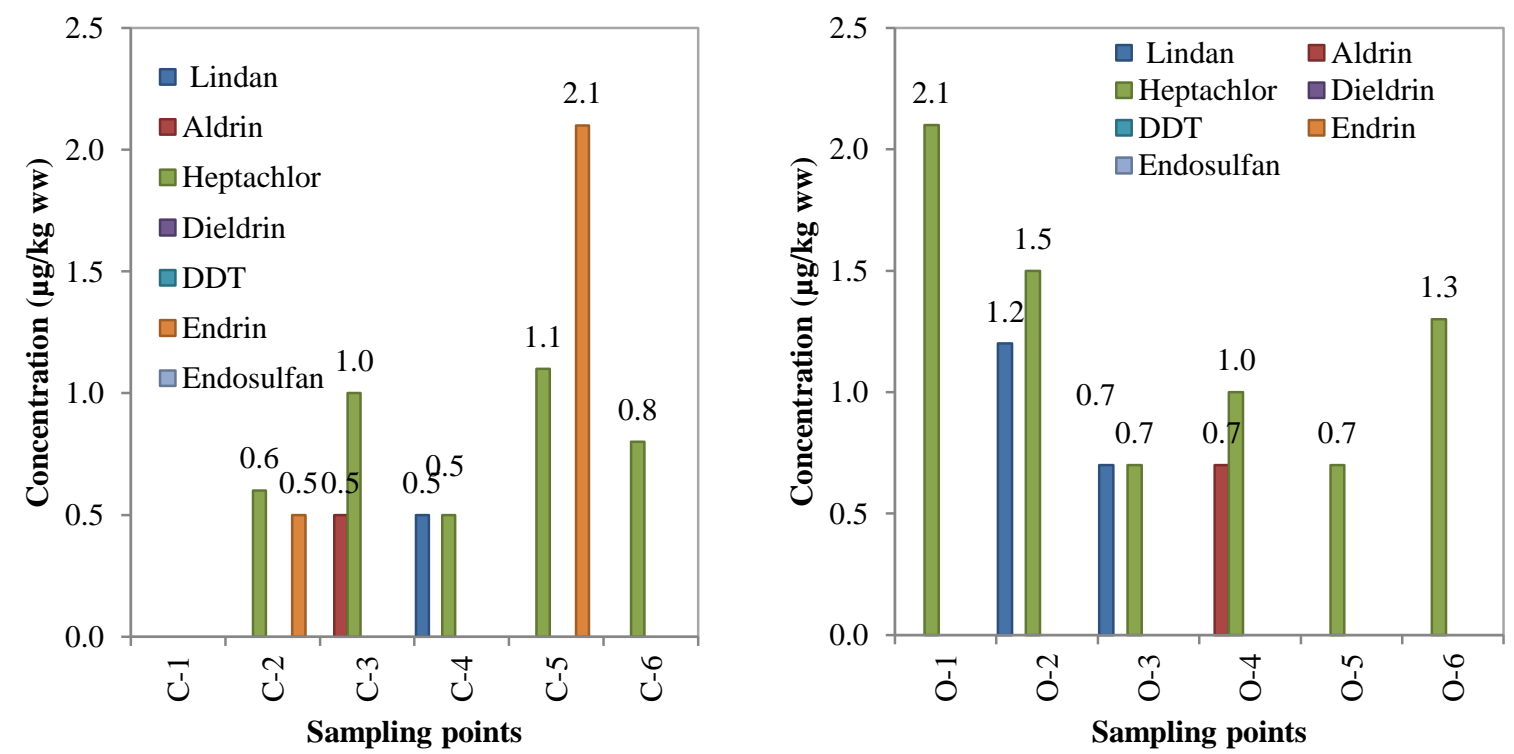

Figure 2. OCPs residue in soil taken from potatoes area of organic farm $(O)$ and conventional farm $(C)$

The varieties of OCP residue of soil samples in this study were different compared to the previous study. Lindane and heptachlor were dominating in this study while dieldrin, heptachlor and 
endosulfan were dominating in the agricultural area for vegetables and paddy field at Kertasari subdistrict (Yunike, 2009 and Deviyani, 2010). Endosulfan was still used according to the questionnaires which were collected from the farmers from Kartasari subdistrict in 2009. Furthermore, DDT, dieldrin, heptachlor, aldrin, and BHC were detected from pesticide solution which was used to spray carrots (Rochmanti, 2009). Endosulfan was started to be banned and not used at the end of 2009. However, according to the investigation from several pesticide shops, they still have the stock of endosulfan and sell it to the farmers.

Variety and residue of OCP in potatoes and carrots were different. These suggest the differences of chemical used, characteristics and crop species were most important in determining uptake. Plant lipid plays the major factor causing differences observed in plant uptake of lipophilic contaminant such as aldrin, dieldrin, heptachlor and heptachlor epoxide (Chiou, et al., 2001). In addition, the soil-plant transfer of persistent organic chemical residues will depend on the physical and chemical characteristics of the soils. Beck et al. (1996) reported that organic matter and moisture content of the soil are factors frequently reported to exert greatest impact on the availability of soil-sorbed nonionic organic chemical residues to be uptaken by the crops. Generally, the uptake by crop would be favored under moist conditions with low organic matter content in soils. In dry soils with high organics matters, the chemical residues will be strongly bound by the soil rather than being uptaken by the plant. In this study, soil organic matter was not investigated. Soil $\mathrm{pH}$ ranged from $6.8-7$ which was not considered to influence the OCP residue. All of factors that might influence will combine in complex ways to control the uptake of chemicals from the soil in to the carrots and potatoes. It cannot be explained in more detail due to the limited number of samples. Further studies should be conducted to ascertain the main factors which influence the OCP uptake by different kinds of crops and the risks from OCP contamination in food stuffs.

\subsection{Risk Analysis}

Potatoes consumption rate was calculated with linear rate assumption based on BPS statistic bureau data from 2004 to 2009, therefore the consumption on year 2010 was $2.21 \mathrm{~kg} / \mathrm{capita}$-year. Carrot consumption rate $(0.83 \mathrm{~kg} /$ capita-year) was selected from 2005 data (Pasaribu, 2007). Comparison of EDI in vegetable with Acceptable Daily Intake (ADI) is shown in Table 5. Overall, EDI was below ADI value. Potatoes have higher EDI than carrot, since consumption rate and OCP average concentration of potatoes was higher compare to carrot. While Chronic effects were determined by comparing EDI with Minimal Risk Level (MRL) formulated by US FDA. Comparison result is 
summarized in Table 6. EDI of carrot and potatoes from current research were far below the MRLs for acute, intermediate and chronic effects.

Table 5. Comparison between EDI of vegetables samples with ADI value

\begin{tabular}{|c|c|c|c|c|c|}
\hline \multirow{2}{*}{ Chemical } & \multicolumn{2}{|c|}{ Carrot (ng/kg bw-day) } & \multicolumn{2}{|c|}{ Potatoes (ng/kg bw-day) } & \multirow{2}{*}{ ADI [ng/kg b.w] } \\
\hline & Organic & Conventional & Organic & Conventional & \\
\hline Lindane & 0.04 & 0.06 & 0.21 & 0.66 & 1000 \\
\hline Aldrin & n.c $\mathrm{c}^{\mathrm{a}}$ & 0.09 & 0.48 & n.c & 100 \\
\hline Heptachlor & 0.02 & 0.08 & 0.14 & 0.07 & 100 \\
\hline Dieldrin & 0.09 & 0.05 & n.c & n.c & 100 \\
\hline DDT & 0.02 & n.c & n.c & n.c & 2000 \\
\hline Endrin & 0.03 & 0.04 & 0.07 & n.c & 2000 \\
\hline Endosulfan & n.c & n.c & 0.06 & n.c & 6000 \\
\hline
\end{tabular}

Table 6. Comparison EDI value of OCPs in vegetables samples with MRL formulated by US FDA

\begin{tabular}{|c|c|c|c|c|c|c|c|c|c|}
\hline \multirow[t]{2}{*}{ Chemical } & \multirow[t]{2}{*}{ Route } & \multicolumn{2}{|c|}{$\begin{array}{c}\text { Carrot } \\
\text { (ng/kg bw-day) }\end{array}$} & \multicolumn{2}{|c|}{$\begin{array}{c}\text { Potatoes } \\
\text { (ng/kg bw-day) }\end{array}$} & \multirow[t]{2}{*}{ Duration } & \multirow[t]{2}{*}{ MRL [ng/kg/day] } & \multirow[t]{2}{*}{ Factors } & \multirow[t]{2}{*}{ Endpoint } \\
\hline & & Org. & Conv. & Org. & Conv. & & & & \\
\hline \multirow[t]{2}{*}{ Lindane } & Oral & 0.04 & 0.06 & 0.21 & 0.66 & Acute & 3000 & 300 & Developmental. \\
\hline & & & & & & Intermediate & 10 & 1000 & Immunological. \\
\hline \multirow[t]{2}{*}{ Aldrin } & Oral & n.ca & 0.09 & 0.48 & n.c & Acute & 2000 & 1000 & Developmental. \\
\hline & & & & & & Chronic & 30 & 1000 & Hepatic \\
\hline \multirow[t]{2}{*}{ Heptachlor } & Oral & 0.02 & 0.08 & 0.14 & 0.07 & Acute & 600 & 3000 & Reproductive \\
\hline & & & & & & Intermediate & 100 & 300 & Immunological. \\
\hline \multirow[t]{2}{*}{ Dieldrin } & Oral & 0.09 & 0.05 & n.c & n.c & Intermediate & 100 & 100 & Neurological. \\
\hline & & & & & & Chronic & 50 & 100 & Hepatic \\
\hline \multirow[t]{2}{*}{ p,p' DDT } & Oral & 0.02 & n.c & n.c & n.c & Acute & 500 & 1000 & Developmental. \\
\hline & & & & & & Intermediate & 500 & 100 & Hepatic \\
\hline \multirow[t]{2}{*}{ Endrin } & Oral & 0.03 & 0.04 & 0.07 & n.c & Intermediate & 2000 & 100 & Neurological. \\
\hline & & & & & & Chronic & 300 & 100 & Neurological. \\
\hline \multirow[t]{2}{*}{ Endosulfan } & Oral & n.c & n.c & 0.06 & n.c & Intermediate & 5000 & 100 & Immunological. \\
\hline & & & & & & Chronic & 2000 & 100 & Hepatic \\
\hline
\end{tabular}

${ }^{a}$ n.c not calculated

Risk characterization, non-carcinogenic was calculated by dividing EDI with the reference dose (RfD), as shown in Table 2. While for carcinogenic effects, the risk calculation was determined by multiplying the CDI with Slope Factor (SF) (Table 1).

Hazard quotient (HQ) of each OCPs and hazard index (HI) as total hazard quotient of carrot and potatoes samples from this study is described in Figure 3. HQ and HI of carrot and potatoes from both farms were below unity. These results suggested that there might not be a concern for potential noncancer effects. As consequences, there was possibility of chronic effect. In case of carcinogenic effect, risk value of each OCP was determined by multiplying the intake (EDI) with the SF (Slope factor). The risk calculation of each OCPs and total risk of OCPs are shown in Figure 4.

According to Figure 4, risk of each OCP was below the recommended risk by EPA $\left(10^{-6}\right)$. However, potatoes have higher risk compare to carrot samples. Aldrin was found as the highest cancer risk for carrot from conventional farm and potatoes from organic farm. Dieldrin was found having higher risk in carrot from organic farm. Although lindane was dominating in samples, higher risk was 
found in potatoes samples from conventional farm. Total risk of potatoes from organic farm was above the recommended risk by EPA. Therefore, there was probability of individual developing cancer over a lifetime as a result of OCPs exposure from potatoes consumption.

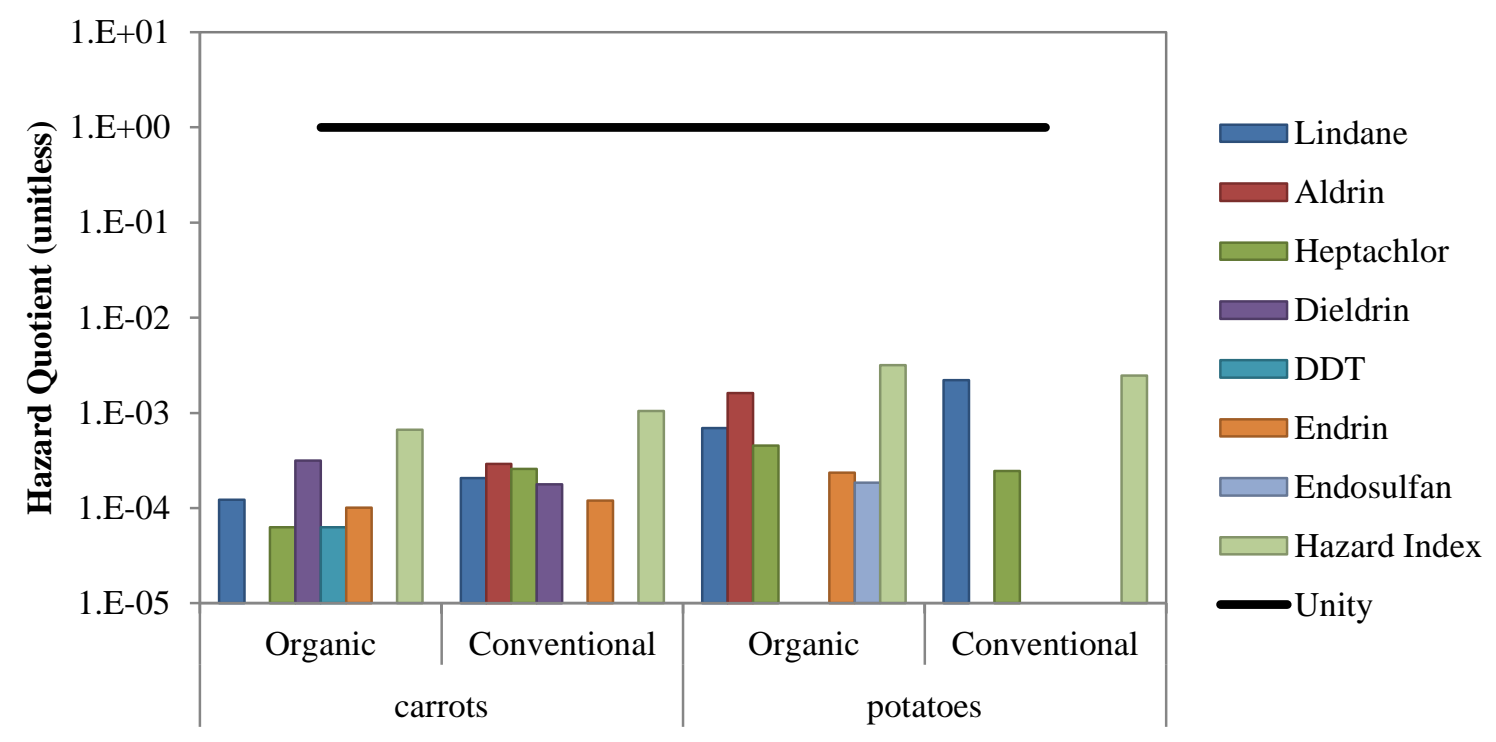

Figure 3. Hazard Quotient (HQ) of OCP residue in potatoes and carrots

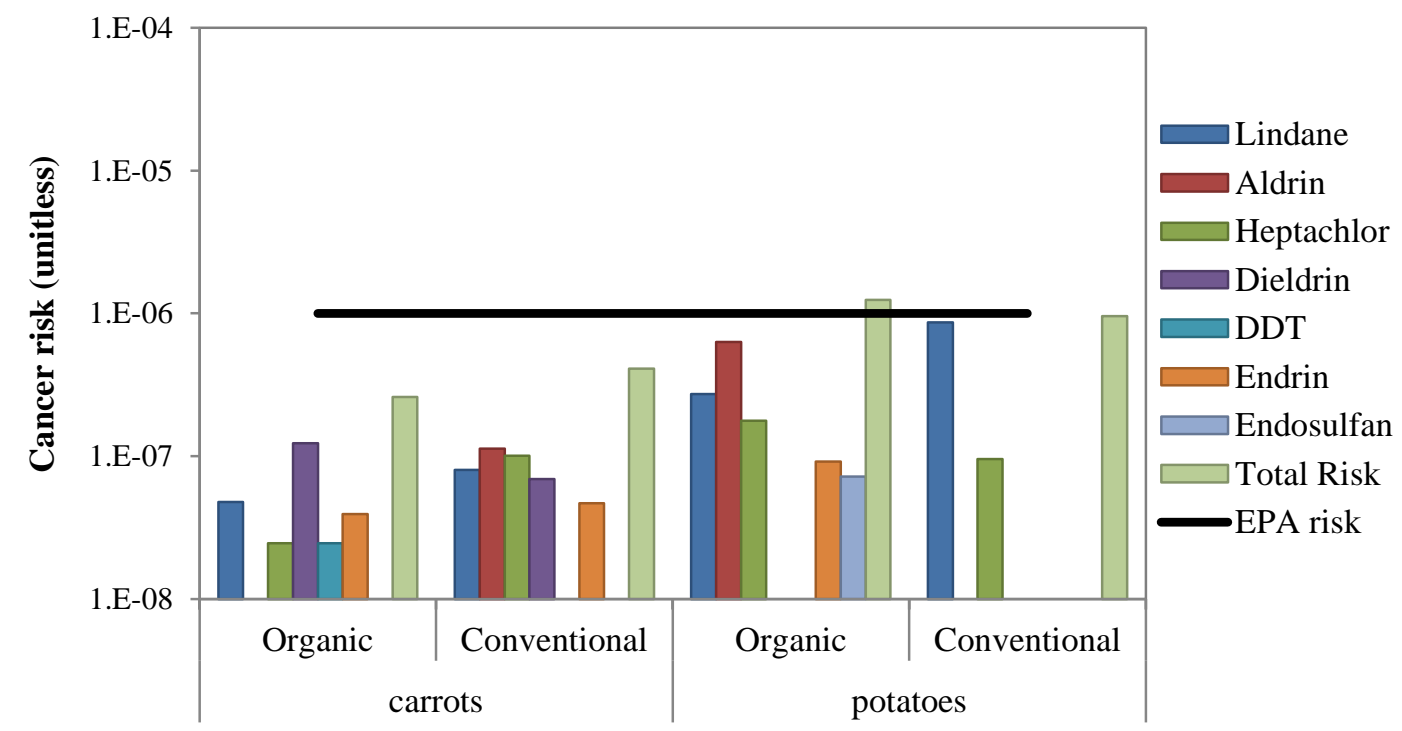

Figure 4. Cancer Risk of OCP residue in potatoes and carrots

\section{CONCLUSION}

Current study showed that OCP residues were detected in carrots and potatoes from organic farming. OCP residue in potatoes from conventional farm was significantly different compared with organic farm. On the other hand, OCP concentration in carrots from conventional farm was almost similar with carrots from organic farm. DDT was detected in soil and crops from organic farm; this was probably from pre-organic farming or surrounding area. OCP uptake depended on the crop varieties 
but further research is needed to observe whether it is related with the characteristic of crops or as a reflection of the variability of OCP residue in the soils which the different crops are grown.

From risk analysis results, EDI of potatoes and carrots were far below ADI and MRLs. HQ and HI as effect analysis were below the unity, thus there may not be a concern for non-carcinogenic effect. Risk analysis on cancer effects indicated that potatoes samples were above the recommended risk given by EPA $\left(10^{-6}\right)$. In addition, risk of potatoes samples from organic samples was higher compare to that of the conventional farm. Cancer risk analysis of carrot samples were found below the recommended risk given by EPA. Cancer risk effect of carrot samples from conventional farm was slightly higher compared to carrot samples from organic samples.

\section{REFERENCES}

Agency for Toxic Substancess and Diseases Registry (ATSDR), (2010), Minimal Risk Levels (MRLs) for Hazardous Substances, http://www.atsdr.cdc.gov/mrls/mrllist.asp , Accessed 1 September 2011.

Beck, AJ., Johnston, DL., and Jones, KC., (1996), The form and bioavailability of non-ionic organic chemicals in sewage sludge amended soils, Sci. Total Environ.,185(1-3),pp. 125-49.

Chiou, CT., Guangyou, S., and Manes, M., (2001), A partition-limited model for the plant upatake of organic contaminants from soil and water, Environ. Sci. Technol., 35(7), pp.1437-1444.

Deviyani, (2009), Organochlorine Insecticide Residue in The Upper Citarum Watershed and Its effect on Earthworm as an Impact of The Used of Persistent Organic Pollutant in The Environment, Master Thesis, Department of Environmental Engineering Institut Teknologi Bandung, Indonesia.

Environmental Protection Agency (EPA), (1986), Guidelines for the Health Risk Assessment of Chemical Mixtures Risk Assessment Forum, U.S. Environmental Protection Agency, Washington, DC.

Gonzales, M., Miglioranza, KS., Aizpún de Moreno, JE., Moreno, VJ., (2003), Occurrence and distribution of organochlorine pepticides (OSPs) in Tomato (Lycopersion esculentum) crops from organic production, J. Agric. Food Chem, 51(5), pp.1353-1359.

Hildebrandt, A., Lacorte, S., and Barceló, D., (2009), Occurrence and Fate of Organochlorinated Pesticides and PAH in Agricultural Soils from the Ebro River Basin, Arch. Environ.Contam. Toxicol., 57(2), pp. 247-55.

Huddleston, JH., (1994), How soil properties affect groundwater vulnerability to pesticide contamination. The Oregon state University, Extention Service. 
Imo, ST., Hirosawa, E., Sheikh, MA., Tamaki, F., and Oomori, T., (2006), Persistent organochlorine pesticides (OCPs) in river waters of southern part of Okinawa Island, Japan. Asian Journal Water, Environment and Pollution, 4(2), pp. 37-42.

Integrated Risk Information System (IRIS), (2011), A-Z List of Substances.

International Programme on Chemical Safety (IPCS), (2006), Inventory of IPCS and other WHO pesticide evaluation and summary of toxicological evaluations performed by the joint meeting on pesticide residue (JMPR).

Jiang, YF., Wang, XT., Jia, Y., Wang, F., Wu, MH., Sheng, GY., and Fua, JM., (2009), Occurrence, distribution and possible sources of organochlorine pesticides in agricultural soil of Shanghai, China, Journal of Hazardous Materials, 170(2-3), pp.989-997.

Li, XH., Wang, W., Wang, J., Cao, XL., Wang, XF., Liu, JC., Liu, XF., Xu, XB., Jiang, $\mathrm{XN}$,(2008), Contamination of soils with organochlorine pesticides in urban parks in Beijing, China, Chemosphere, 70 (9), pp.1660-1668.

Munawir, K., (1996), Pemantauan kadar pestisida organoklorin dalam air dan sedimen di perairan Muara Sungai Siak, Puslit Oseanografi LIPI, pp. 147-152.

Munawir, K., (2000), Kadar pestisida organoklorin dalam air dan sedimen di perairan Sulawesi Utara, Puslit Oseanografi LIPI.

Munawir, K., (2005), Kadar pestisida organoklorin dalam air dan sedimen di perairan estuarine Membramo, Irian Jaya, Oceanology and Limnology Journal of Indonesia ISSN 0125-9830, 38, pp. 69-78.

Pasaribu, P., (2007) Analisis Pendapatan dan Faktor-Faktor yang Mempengaruhi Produksi Usahatani Wortel Di Kabupaten Tegal, Skripsi, Fak.Pertanian, IPB, Bogor.

Patlak, M., (1996), A resting deadline for endocrine diruptors. Enciron. Sci. Technol, 30, ppt. 540544.

Rochmanti, MD., (2009), Pesticides usage identification at paddy and vegetables fields, case study: Kertasari subdistrict Bandung region, Institut Teknologi Bandung, Indonesia.

Sabdono, A., Rochaddi, B., Chrisna, AS., Susanti, BT., (2008), Persistent organochlorine residues in households wells of Java coastral urban areas, Indonesia, J Applied Sciences, 8 (12), pp.2318-2323.

Samoh, ANH., Ibrahim, MS., (2009) Organochlorine pesticide residues in the major rivers of southern Thailand, The Malaysian Journal of Analytical Sciences, 12(2), pp. 280 - 284.

Shegunova, P., Klánová, J., and Holoubek, I., (2007), Residues of organochlorinated pesticides in soils from the Czech Republic. Environmental Pollution, 146, pp.257-261. 
Standar Nasional Indonesia (SNI) No. 7313:2008 tentang Batas maksimum residu pestisida pada hasil pertanian

Sudaryanto, A., Monirith, I., Natsuko, K., Shin, T., Philippus, H., Muawanah, Koji, O., Hidetaka, T., and Shinsuke, T., (2006), Levels and distribution of organochlorines in fish from Indonesia, Environment International, 33(6), pp.750-758.

Tang, Z., Zhifeng, Y., Zhenyao, S., Junfeng, N., and Renfei, L., (2007), Distribution and sources of organochlorine pesticide in sediments from typical catchment of the Yangtze River, China. Archives of Environ Contam Toxicol ,53(3), pp. 303-312.

USEPA, (1989), Risk Assessment Guidance for Superfund Volume I Human Health Evaluation Manual, Part A, Washington.

Van der Werf, HMG., (1996), Assessing the impact of pesticides on the environment, Agriculture, Ecosystems and Environment, 60 (2-3), pp.81-96.

Wania, F., and Mackay, D., (1996), Tracking the distribution of persistent organic pollutants, Environ Sci Technol., 30, pp. 390-396.

WHO, (1987), Principles for safety assessment of food additives and contaminants in food, Environmental Health Criteria 70.

Yunike, V., (2009), Insecticides Organochlorine Residue Analysis in Vegetables Farming Soil in Kertasari Sub District Bandung Regency West Java Province, undergraduate thesis, Institut Teknologi Bandung, Indonesia.

Zou, R., Zhu, L., Yang, K., and Chen, Y., (2006) Distribution of organochlorine pesticide in surface water and sediments from Qiantang River, East China, J. Hazardous Materials, 137(1), pp. $68-75$ 